\title{
Un breve de Inocencio VIII dirigido a los Reyes Católicos, que nunca recibieron, y la financiación de los Santos Lugares
}

\section{A papal brief from Innocent VIII to the Spanish Catholic Monarchs, which they never received, and funding of the Holy Places}

\author{
Víctor DE LAMA \\ Universidad Complutense Madrid \\ victordelama@pdi.ucm.es
}

Recibido: 6/03/2014

Aceptado: 16/05/2014

\section{RESUMEN}

La Custodia de Tierra Santa requería aportaciones constantes de dinero para acoger a los peregrinos y conservar en buen estado los santuarios confiados a los frailes franciscanos. Cuando mueren sus fundadores Roberto de Anjou y Sancha de Sicilia, sólo las limosnas de los peregrinos y la generosidad de algunos monarcas permitió sostener esa comunidad de frailes que formaba la Custodia desde 1342. En 1487 el papa Inocencio VIII, mediante un breve dirigido a los Reyes Católicos y a otros monarcas, pretendió dar una solución duradera al problema de la financiación, pero no lo consintieron quienes defendían la observancia de la regla de la orden seráfica. En consecuencia, fueron los Reyes Católicos y sus sucesores quienes asumieron voluntariamente ese sostenimiento en forma de limosnas anuales.

Palabras clave: Inocencio VIII, Reyes Católicos, Custodia, Tierra Santa, franciscanos, financiación.

\begin{abstract}
The "Custody" or care of Holy Land required constant cash contributions to welcome pilgrims and to keep the sanctuaries entrusted to the Franciscan friars in good conditions. When its founders Robert of Anjou and Sancha of Sicily died, only the alms of the pilgrims and the generosity of some monarchs maintained the community of monks that formed the Custody from 1342. In 1487 Pope Innocent VIII, in a papal brief addressed to the Spanish Catholic Monarchs and other monarchs, tried to find a permanent solution to the funding problem, but those who followed the observance of the rule of the Seraphic Order did not agree with his proposal. It was the Catholic Kings and their successors who finally contributed to this support, in the form of annual alms.
\end{abstract}

Key words: Innocent VIII, Catholic Monarchs, Custody, Holy Land, Franciscans, funding. 
Bien conocida es por los historiadores la generosidad de Isabel la Católica con los Santos Lugares de Jerusalén. En más de una ocasión sus limosnas ayudaron a su mantenimiento y otras actuaciones semejantes de la corona española, anteriores y posteriores a la Reina Católica, demuestran la especial vinculación económica de España con los Santos Lugares de Palestina. Aunque estas afirmaciones no son novedosas, conviene documentarlas y contextualizarlas adecuadamente para conocer su significación. Y para ello conviene otorgar el valor adecuado a un breve del Papa Inocencio VIII, que no llegó a su destino y que quizá por eso ha pasado prácticamente desapercibido. Dicho escrito marca un hito muy importante en la historia de la financiación de los frailes de la Custodia de Tierra Santa y explica, en buena medida, por qué la Reina Católica asumió su financiación mucho antes de que Fernando el Católico consiguiera el título, con carácter hereditario, de Rey de Jerusalén.

La vinculación de los monarcas castellanos con Tierra Santa no fue en la Edad Media tan estrecha como la de los aragoneses, quienes desde finales del siglo XIII establecieron numerosos acuerdos con los sultanes mamelucos ${ }^{1}$. Pero esa relación podemos remontarla al menos al testamento de Alfonso X el Sabio, en el que se determinó que su corazón fuera llevado a Jerusalén, junto con sus armas y mil marcos de plata para que fundaran con ellos Capellanías en el Santo Sepulcro². Se dice que Enrique III realizó una donación importante para restaurar el convento de Monte Sión y que Enrique IV, ante una expulsión de los franciscanos del Cenáculo, amenazó con la demolición de las mezquitas de sus reinos y la expulsión de ochocientos mil moros de sus dominios ${ }^{3}$. Mucho más estrechas y mejor documentadas están las relaciones que se produjeron entre los monarcas aragoneses y los soldanes mamelucos que poseían toda Palestina donde se encontraban los Lugares Santos.

Los numerosos testimonios de la intensa relación de la reina Isabel con la orden franciscana, y por extensión con Tierra Santa, no podemos reseñarlos en las breves páginas de este artículo. Tampoco es imprescindible, pues ya fueron recogidos por J. Meseguer Fernández en dos enjundiosos artículos: "Franciscanismo de Isabel la Católica" e "Isabel la Católica y los franciscanos (1451-1476). Por otro lado, los donativos de la reina Católica están bien documentados por los cronistas y también son conocidos los diferentes estudios y colecciones de textos sobre la diplomacia de los Reyes Católicos, en especial los reunidos por Antonio de la Torre y del Cerro en sus Documentos sobre relaciones internacionales de los Reyes Católicos.

Ya en 1477 la reina Isabel realizó en Sevilla "un segundo donativo" anual de 300 florines mediante un documento del que tomo algunos párrafos:

Nos Isabel, por la gracia de Dios, Reina de Castilla, de León, de Toledo, de Sicilia, ... habiendo llegado a nuestra noticia que el Guardián y convento de Frailes de la Orden de Menores de Monte Sión, en Jerusalén y los de los demás lugares de

\footnotetext{
${ }^{1}$ Hago un resumen de dichos acuerdos en mi libro Relatos de viajes por Egipto, pp. 45-53.

${ }^{2}$ Dicho testamento fue firmado en Sevilla el 22 de enero de 1282 y en él se lee: "Otrosí, mandamos que luego que muriéremos, que nos saquen el corazón y le lleven a Tierra santa de Ultramar e que lo sotierren en Jerusalén, en el Monte Calvario, allí yacen algunos de nuestros abuelos" (MondÉJAR, Memorias históricas del Rey Don Alonso el Sabio, Madrid, 1777, pp. 434-435)

${ }^{3}$ Ramos-Lissón, "Jerusalén en el medievo español desde una perspectiva cristiana", Scripta theologica, $41(2009 / 3)$, p. 942.
} 
Tierra Santa, están necesitados de no mediana ayuda, no sólo para atender al propio alimento, sino además para construcción y reparación de sus templos, debiendo, por lo mismo, ser socorridos por los Reyes, Príncipes y demás fieles de Cristo, a fin de que puedan fabricar, reparar y mejorar los dichos lugares. Por esta causa, Nos, motu proprio, deliberado y previo consejo a los ya dichos Guardián, convento y Frailes de Monte Sión, en Jerusalén, damos, donamos, entregamos y liberalmente dispensamos, a perpetuidad, por el tenor de las presentes, trescientos florines, que han de deducirse de los ingresos, emolumentos y Stadennis [¿medidas?] tanto ordinarios como extraordinarios de otros cualesquiera, relativos a nuestra Real Cámara del Reino de Sicilia... Dadas en la nobilísima Ciudad de Sevilla el día 20 del mes de septiembre del año del Señor, 1477. Yo, la Reina ${ }^{4}$.

No sabemos cuándo se efectuó la primera donación, pero es evidente que la reina castellana heredó de sus antepasados una consideración muy especial con los franciscanos que custodiaban el Santo Sepulcro. Tras la toma de Málaga, en el verano de 1489, llegó una embajada a los Reyes Católicos procedente de Egipto, cuando estaban preparando el cerco de Baza, la última operación para la conquista de Granada. Formaban la legación tres franciscanos de Tierra Santa, entre ellos el padre Fray Antonio Millán, Superior o Vicario de los franciscanos que vivían en Jerusalén. Habían pasado previamente por la corte de Ferrante de Nápoles y de Inocencio VIII en Roma. El sultán de Egipto les había confiado un encargo comprometido que el historiador Zurita recoge con estas palabras:

Si los reyes de España no alzasen la mano de perseguir por las armas a los moros que estaban en Granada y su reino, mandaría derribar los templos e iglesias que había en su reino, hasta destruir el Sepulcro Santo de Jerusalén ${ }^{5}$.

Los reyes no accedieron a detener su campaña, pues consideraban que la guerra de Granada era puramente política y justa desde hacía más de setecientos años. Junto a esa respuesta tan poco complaciente para el soldán, la reina Católica adquiría con los franciscanos de Tierra Santa un compromiso económico sustancioso. El 24 de agosto de 1489 Isabel firmaba un documento en Jaén por el cual hacía entrega de una cantidad anual de mil ducados de oro para el sostenimiento de los Santos Lugares, recursos que saldrían de la aduana de la ciudad de Mesina, en Sicilia ${ }^{6}$. Por la fecha, es probable que esta partida sea la otorgada a la embajada de tres franciscanos que se presentó en el campamento castellano en aquel verano. Seguramente la reina demostraba así su agradecimiento por el curso de la contienda con contra los sultanes

4 El texto completo, en latín y en castellano, puede verse en Euján, El Real Patronato de los Santos Lugares, I, pp. 219-221. Recoge también el texto TORRE Y DEL CERRo, Documentos inéditos para la Historia de España, VII, pp. 3-4.

5 Recogido por Eusán en Hispanidad en Tierra Santa, p. 33.

${ }^{6}$ Documentos inéditos para la Historia de España, VII, pp. 276-278. CAlahorra certifica estos datos con exactitud anotando que, "entendida la necesidad que padecían los Santos Lugares de la Católica Reina de España Doña Isabel, mandó que para reparos del convento del sacro Monte Sión y sustento de los religiosos, se diesen de su Cámara Real del Reino de Sicilia, cada año mil ducados de oro, de lo cual consta por una escritura que se conserva en el archivo d'este Santo Convento, fecha en Jaén a 24 de agosto, año de 1489". Chrónica de la provincia de Syria y Tierra Santa de Gerusalén, p. 311. 
nazaríes y los embajadores franciscanos se llevaron también "un velo bordado en oro por la Reina, como regalo para la iglesia del Santo Sepulcro de Jerusalén"7.

Dichas entregas fueron ratificadas bastante después, el 12 de mayo de 1507, por Fernando el Católico "a fin de que en ellos vaya en aumento el divino culto y los religiosos que allí moráis os fatiguéis menos en procurarlo". Abundan los testimonios sobre esta ayuda económica de los monarcas españoles, pero quiero destacar uno muy expresivo, de 1515, cuando todavía vive el Rey Católico. Se lo debemos a Francesco Suriano, que fue dos veces Custodio de Tierra Santa (entre 1493 y 1495 y luego entre 1512 y 1515) y que asegura en su Trattato della Terra Santa que se siguen pagando los dos mil ducados de oro venecianos cada año establecidos por la Reina Católica y cómo "questa elymosina medesima ha facta e fa il suo succesore ne l'anni del Signor mille cinquecento quindece. Di li qual denari vivono al presente li frati"'. Antonio de Aranda en la época del Emperador ${ }^{10}$ y Blas de Buyza en la de Felipe III ${ }^{11}$ recuerdan también la periodicidad de esos auxilios econónicos. El cronista Juan de Calahorra, que escribe a finales del siglo XVII, ratifica la información señalando el compromiso permanente de esa contribución:

La cual limosna continúan hasta el día de hoy (sin otras muchas dignas de su magnificencia real) los Reyes Católicos por el singular afecto y piedad con que atienden a la conservación de los Lugares Santos"12.

Por otro lado Fernando el Católico, tras las guerras contra los franceses libradas en los primeros años del siglo XVI, se hizo acreedor del título de Rey de Jerusalén en virtud de los derechos dinásticos de la corona de Aragón ${ }^{13}$. Dicho título lo reconoció el papa Julio II, en nombre de la Iglesia, en virtud de una bula fechada el 3 de julio de 1510. Lo heredó Carlos I y, su hijo Felipe II y luego todos los monarcas españoles hasta hoy. Desde que la reina Católica estableciera aquella renta en 1489, todos sus herederos como reyes de Jerusalén asumieron dicha obligación. Así lo recuerda fray Antonio de Aranda en su Verdadera información de la Tierra Santa, publicada en 1533:

\footnotetext{
${ }^{7}$ Ochoa Brun, Historia de la Diplomacia Española, IV, p. 143

${ }^{8}$ Documentos inéditos..., VII, pp. 248-251.

${ }^{9}$ En su Trattato della Terra Santa, Milán, 1900, p.111 (citado por EIJ́́n, El Real Patronato, I, p. 226).

${ }^{10}$ Aranda, Verdadera información de la Tierra Sancta según la disposición en que en el año de mil y quinientos y treinta el autor la vio y passeó. Alcalá de Henares, Miguel de Eguía, 1533.

${ }^{11}$ Buyza, Relación nueva y copiosa de los sagrados lugares de Ierusalén y Tierra Santa.

${ }^{12}$ CALAHORRA se refiere no solo a Isabel y Fernando sino a todos los monarcas de la casa de Austria (Chrónica de la provincia de Syria y Tierra Santa de Gerusalén, p. 311).

${ }^{13}$ El Reino de Jerusalén remonta sus orígenes a la Navidad del año 1100 cuando Balduino I, el hermano de Godofredo de Bouillon, se ciñó aquella corona. De los descendientes de Balduino los derechos pasaron a los Staufen y luego a Pedro III de Aragón por su matrimonio con Constanza. Otras fuentes vinculan los derechos a Roberto de Anjou y Sancha de Sicilia quienes, mediante la bula Gratias agimus, fueron nombrados patronos de Jerusalén. Los derechos acabaron recayendo en Alfonso V de Aragón (el Magnánimo) y luego en Fernando el Católico (SÁnchez Prieto, "La intitulación diplomática de los Reyes Católicos, pp. 273-301). La cuestión llegó a ser tan controvertida que dio lugar al Tratado de la sucessión de los reinos de Jerusalén y de Nápoles, impreso en Zaragoza en 1503, que el Comendador Cristóbal de Santisteban dirige a la reina Isabel. Véase ahora el estudio de GÓmez Redondo en su Historia de la prosa de los Reyes Católicos, pp. 332-340.
} 
En este convento están religiosos de todas las principales naciones latinas, así como de Italia, Francia, España, Alemania, Polonia, Hungría, Esclavonia...Solo se mantienen los religiosos con la limosna anual que la católica Reina, nuestra doña Isabel, según que daba en vida, mandó en su testamento que cada año se diese para la sustentación de los frailes de San Francisco, moradores de Sión y para aceite de las lámparas del Santo Sepulcro.

Diversas manifestaciones posteriores de viajeros y estudiosos demuestran que la protección de los frailes de la Custodia por parte de la corona española se mantuvo sin interrupción ${ }^{14}$. Una especial vinculación de la Corona de Aragón con Tierra Santa tuvo su comienzo cuando los Reyes de Nápoles Roberto de Anjou (1278-1343) y su esposa Sancha de Sicilia (o de Mallorca) (1285-1345) llegaron a un acuerdo económico con el sultán mameluco para que permitiera a los frailes franciscanos establecerse en Jerusalén en varios santuarios que se construirían con la financiación de los citados reyes de Nápoles: el de Monte Sión, una parte del Santo Sepulcro y la Gruta de la Natividad. Clemente VI, mediante la bula Gratias agimus, expedida en Aviñón el 21 de noviembre de 1342, concedía la Custodia de Tierra Santa a los franciscanos. El Guardián de Monte Sión, santuario donde se establecieron los doce primeros frailes, era el representante del Papa en Tierra Santa y tenía algunas de sus prerrogativas.

No es fácil precisar de dónde llegó la ayuda a estos frailes franciscanos cuando murieron sus fundadores y protectores, pues al morir sin descendientes directos, se produjeron muchas desavenencias. Las ayudas de los peregrinos latinos nunca bastaron para el mantenimiento y restauración de aquellos edificios que tutelaban, que además fueron en aumento, pues en 1363 la reina Juana de Nápoles obtiene del sultán la tumba de la Virgen en el Valle de Josafat y antes de terminar el siglo otros lugares santos. No sólo había que dar alojamiento y comida a todos los frailes cuyo número fue creciendo igualmente. De doce frailes en 1342, ascendieron a veinte a finales del siglo XIV, a treinta en el reinado de Carlos I (según confiesa fray Antonio de Aranda), a cien en el reinado de Felipe IV y a ciento cincuenta en el de Felipe $\mathrm{V}^{15}$. El rey de Aragón Pedro IV, ya antes de morir doña Sancha de Sicilia, fue autorizado en virtud del breve Rex Regum (10-3-1345) a restaurar el convento de Monte Sión, construido por aquella; luego en 1366 interviene ante Inocencio VI para reparar ese santuario, además de conseguir autorización para construir a los franciscanos el convento de Getsemaní, junto al Sepulcro de la Virgen ${ }^{16}$.

Lo más costoso fue siempre la conservación y reparación de los edificios. Cronistas y viajeros dan cuenta de esta actividad durante el reinado de los Reyes Católicos ${ }^{17}$. Una de las primeras obras fue la del santuario de Belén, realizada bajo el mandato de Juan de Tomaselis, que fue nombrado Guardián de Monte Sión en el Capítulo General celebrado en Pavía el 10 de abril de 1478, "hijo de la Santa Provincia de San

\footnotetext{
14 Muchos documentos pueden leerse en las páginas de Euján, El Real Patronato de los Santos Lugares.

15 Eı́án, El Real Patronato de los Santos Lugares, I, p. 83.

16 Eıján, Hispanidad en Tierra Santa, p. 29.

${ }_{17}$ El Cruzado que tuvo que viajar en torno a 1483-1485 menciona, por ejemplo, la reparación del templo de Belén.
} 
Antonio, religioso doctíssimo y de noble familia entre los napolitanos". Su labor fue muy importante:

Perficionó este buen padre, con grande industria y desvelo, la fábrica que avían començado sus antecesores en el convento de Santa María del Pesebre, en la ciudad de Belén, y renovó todo el techo de aquella sumptuosa iglesia, que está edificado sobre el sacratísimo lugar del nacimiento de Cristo nuestro Redemptor, sirviéndose para esta fábrica de los materiales que a costa de grandísimo precio avía comprado en Venecia y llevado a la santa ciudad de Gerusalén, el Ilustríssimo Príncipe Filipe, Duque de Borgoña. El maderaje de cedro (gastado ya por su antigüedad) con que avía adornado aquel santíssimo templo el obispo Máximo por orden de Santa Elena y de el Emperador Constantino, le ocultó en la cueva a donde está el sepulcro de los Niños Inocentes, con ánimo de repartirle (por la reverencia de aquel Santo Lugar y Templo) entre los príncipes cristianos $^{18}$, mas llegando a noticia del soldán de Egypto, atajó sus buenos deseos, sacándole de aquel santo lugar y mandando que se llevase a su corte del gran Cairo. No obstante esto, era el soldán muy afecto a los religiosos y así le permitió que reparasse muy a su satisfación aquel santísimo templo, el cual volvió a cubrir, como antes estaba, de planchas de plomo, sirviéndose de las antiguas, y añadiendo aquellas que fueran necesarias de nuevo. Para todo esto le fue de grande alivio un religioso alemán, llamado fray Baptista de Lubige, varón muy ingenioso y en la medicina peritísimo, al cual avía graduado de Doctor, en la dicha facultad, el Pontífice Pío Segundo y le avía embiado a Tierra Santa para que curasse a los Religiosos ${ }^{19}$.

En 1484 es nombrado guardián Fray Bernardino de Parma y durante su mandato se reparó y alargó en la ciudad de Rama el hospicio que regentaban en el camino que iba desde el puerto de Jafa a Jerusalén, un edificio que en opinión de Diego de Mérida podía albergar a unos seiscientos peregrinos hacia $1510^{20}$. Y también en 1497, durante las intrigas y revueltas sucesorias que se desencadenaron en Egipto cuando murió Kait Bey, Fernando el Católico escribió al sultán de turno pidiéndole que consintiese la reparación de una arcada del Santo Sepulcro, que se había caído ${ }^{21}$. Los problemas no desaparecieron, pues entre los acuerdos que logró Pedro Mártir de Anglería en febrero de 1502 del soldán Khansu al Ghuri figuara este:

Que nos fuera permitido restaurar las construcciones antiguas caídas y reparar las que, edificadas en Jerusalén por nuestros antepasados en memoria de Cristo, cayéndose poco a poco, amenazaban ruina. Ya que los sacerdotes mahometanos, desde que arrebataron el poder a los cristianos, no habían consentido nunca su renovación, porque habían persuadido a los anteriores soldanes de que estaba vedado por la ley ma-

18 Obsérvese que esa madera de cedro, sin duda del Líbano y probablemente con antiguas pinturas, era una preciada reliquia para los príncipes que habían costeado las obras. Menos se entiende a primera vista que el soldán Kait Bey también la quisiera para sí, aunque no debe extrañarnos del todo pues sabemos que fue un gran amante de la arquitectura, del arte y también para él tenía el valor como reliquia, ya que la Virgen María era y es venerada con mucha devoción por los musulmanes.

${ }^{19}$ Calahorra, Chrónica de la provincia de Syria y Tierra Santa de Gerusalén, pp. 297-298. En adelante se cita sólo por CALAHORRA y la página.

${ }^{20}$ Diego de Mérida envió desde Candía (Creta) su relato a sus hermanos jerónimos de Guadalupe en 1512, pero su paso por ese albergue debió de producirse un par de años antes.

${ }^{21}$ Torre y del Cerro, Documentos sobre relaciones internacionales de los Reyes Católicos, p. 551. 
hometana. Y además que se consintiera renovar los monumentos, no solo de Jerusalén sino también de Beirut, Rama, Belén y el resto de lugares en los que existiera memoria de los hechos de Cristo $^{22}$.

Los gastos eran muchos y los tributos de los peregrinos no bastaban, a pesar de que durante aquellos años fueron muy numerosos los peregrinos que llegaron a Jerusalén. Inocencio VIII, pontífice entre 1484 y 1492, llevó a cabo una política decididamente antimusulmana. En el plano internacional intentó la organización de una cruzada contra los turcos, pero no tuvo éxito por las rivalidades existentes entre los monarcas cristianos. En el ámbito español concedió a los Reyes Católicos, por mediación de su embajador Íñigo López de Mendoza y Quiñones (el Gran Tendilla) la ampliación de la bula de Cruzada como instrumento financiero para continuar la lucha contra el reino nazarí de Granada. A la vez quiso poner un remedio duradero, en el tercer año de su pontificado, a tantas necesidades de los franciscanos de la Custodia destacados en Jerusalén por lo que,

viendo que por los alborotos de las guerras y otras calamidades de aquellos tiempos se avía enfriado en los fieles la caridad para con los religiosos que servían a los santos lugares, movido del zelo de su conservación y de que no les faltase a los pobres religiosos lo necesario para repararlos y mantenerlos, determinó de ponerles ciertas limosnas perpetuas sobre algunos prioratos y monasterios de España, Francia y del Ducado de Borgoña. Sobre este negocio escribió a los católicos reyes don Fernando y doña Isabel, exortándolos a que favoreciesen tan piadosa determinación, y le diesen noticia de los beneficios o prioratos sobre los cuales pudiese hazer alguna reservación de sus frutos para el dicho intento" (Calahorra, p. 310).

El breve papal no consta en ninguna de las colecciones de documentos diplomáticos de los Reyes Católicos porque no llegó a ser enviado. Lo conocemos, sin embargo, porque el cronista Juan de Calahorra nos lo transmite en 1684, según parece, textualmente. Por considerarlo del máximo interés, lo copio aquí:

Inocencio Obispo \& c.

A los muy amados hijos Fernando y Isabel, reyes Ilustres de Castilla, de León y Aragón. Los Religiosos Franciscos que asisten en Gerusalén a la Custodia de los Lugares Santos y del Santíssimo Sepulcro, carecen (como poco ha nos ha sido referido) de la acostumbrada limosna, que les hazían algunos Príncipes cristianos ya difuntos. De donde proviene que los religiosos no pueden exercitar la hospitalidad ni reparar a aquellos santuarios ni tener las cosas necesarias para el culto divino, ni perseverar allí mucho tiempo, de lo cual nos movemos y atendemos (assí por la santidad del lugar, como por las obras de piedad que allí se exercitan) a proveer de remedio, especialmente porque no se extinga aquella devoción, que ha quedado sola entre tantas naciones bárbaras, enemigas del nombre de Cristo, la cual deben tener a su cargo todos los católicos, porque no se desampare aquel lugar tan célebre y venerable por cuya conservación han vertido tanta sangre nuestros mayores. Por lo cual exortamos y atentamente pedimos a vuestra Serenidades que nos queráis hazer saber, de qué Beneficios, Prioratos o Monasterios (que se dan por encomienda en vuestro reinos y no son asistidos

22 Álvarez- Moreno, Una embajada española al Egipto de principios del siglo XVI pp. 162-164. 
de Comunidad) podemos hazer alguna especial reservación y que tanto (sacados los gastos) podrán dar cada año para que podamos aplicar a la necesidad del dicho lugar sus frutos. De lo cual vuestra majestades consiguirán [sic] delante de Dios (por cuyo honor se haze) gran mérito y alabanza de los fieles de Cristo, que no tienen otro refugio en aquella región. Dat. Romae apud Sanctum Petrum sub annullo piscatoris, die undecima Maii anno 1487, Pontificatus nostri anno tercio.(Calahorra, p. 310)

En los mismos términos escribió al rey de Francia y al príncipe de Borgoña, pero dichas cartas no llegaron a su destino. La razón es muy interesante, pues nos revela a las claras el clima religioso que se vivía entonces, cuando muchos religiosos y no religiosos competían por conseguir rentas vitalicias de iglesias, monasterios, etc. y sin embargo alguien ponía inconvenientes a esa forma de obtener dinero:

El Reverendísimo Padre Fray Juan Sigestro, Vicario General de la Familia Cismontana resistió con gran zelo de la observancia de la regla a semejante determinación diciendo: que por muchos años se avían conservado feliz y abundantemente los religiosos de Tierra Santa con sola su pobreza, y así procuró que no llegassen a las manos de los sobredichos Príncipes las Letras Apostólicas. (Calahorra, p. 311)

Fray Juan Sigestro (1440-1510) fue el cuarto Vicario General de la Observancia Franciscana, concretamente entre 1487 y $1490^{23}$ y, como tal, vio en ese breve pontificio un peligro para la observancia de la regla de la orden seráfica. Según el Patrimonio Seráphico de Tierra Santa, en cuanto Juan Sigestro tuvo noticia de las intenciones del Papa, en Roma mismo se aprestó a impedir que llegara a su destino:

Se rindió a sus pies suplicándole fuesse servido de mudar de intento assegurándole que quien por tantos años había conservado a los Religiosos Menores en aquellos santíssimos lugares sin tales proprios o rentas y solo con la Fe viva en la Altíssima Providencia, los conservaría en adelante hasta el fin del mundo. Que assí lo estaba creyendo, pues fuera de la providencia común, con que Dios assiste a los hijos de San Francisco, esperaba que con mayor empeño avía de asistir su misericordia a los de Tierra Santa, por estar en servicio de aquellos lugares, que con su sangre había santificado. Que no era cosa congruente que habiendo su Magestad fundado allí la pobreza Evangélica y observádola sus Apóstoles; los Menores, que en esta vida apostólica los seguían, y en la misma tierra estaban, tuviesen rentas tan opuestas a lo que avían professado. Que la incomprehensibilidad Divina permitía los presentes ahogos, no creía que era para desampararlos, sino para su mayor mérito en la Fe y para acrisolar su paciencia; pues luego disponía su Magestad los socorros, quando más necessitados, por medio que los hombres no prevenían. Que assí suplicaba a su Beatitud, los dexasse correr sin dispensas, ni faltar en un ápice a su Professión, por quenta de Dios, que assí los quería.

Fueron estas súplicas tan rendidas y valerosas que el Papa mudó de intento aunque procuró aliviarlos con algunas limosnas ${ }^{24}$.

23 Tomo el dato del Regestrum Observantiae Cismontanae: 1464-1488, p. 23.

24 San Juan Del Puerto, Patrimonio Seráphico de Tierra Santa, p. 241. 
Y así se justifica la ayuda dos años más tarde de la Reina Isabel, sabedora de las necesidades por las que pasaban. Sigue explicando el Patrimonio Seráphico de Tierra Santa dónde radica la diferencia en ambas formas de financiación:

Aunque en el material sonido parezca que esta obra pía de los Reyes Católicos coincide con la que intentaba Innocencio VIII, es muy distinta en realidad: porque el Papa transfería la propriedad y dominio phísico de rentas Eclesiásticas en la voluntad de los Religiosos, que es lo que está prohibido por nuestra Regla; y los Reyes Católicos lo dispusieron de forma que en su Real nombre diessen aquellas cantidades los oficiales de su Real Cámara por vía de limosna simple a el Síndico de Tierra Santa, para que, como Limosnero de los mismos Reyes, socorriesse en sus necesidades a los Religiosos, que es el modo natural con que podemos recebir limosnas simples de otra qualquiera persona para sustentar la vida. (Patrimonio Seráphico, pp. 241-242)

Eran los tiempos en que las órdenes mendicantes estaban en pleno proceso de renovación y algunos franciscanos no estaban dispuestos a renunciar a su voto de pobreza, tal como se estipulaba en su regulación monástica; prefirieron seguir viviendo de la caridad, aunque fuese de una reina, antes que recibir unas rentas que ponían en cuestión la observancia de su regla, en un momento en que había otros religiosos que se peleaban por dichos ingresos. La asignación de la Reina Católica seguramente sirvió para financiar año a año las necesidades principales, casi en exclusiva. $\mathrm{Y}$ es que en esa carta de Inocencio VIII, sin duda bienintencionada, se jugaban aquellos seguidores de San Francisco su fidelidad al fundador y el mantenimiento de su voto de pobreza. $Y$ en ese desenlace debemos buscar la razón principal por la que fue la monarquía hispánica, respaldada luego por el título hereditario de Rey de Jerusalén, quien asumió su mantenimiento en forma de limosna.

\section{BIBLIOGRAFÍA}

Álvarez Moreno, Raúl, trad. y ed., Una embajada española al Egipto de principios del siglo XVI: La Legatio Babilónica de Pedro Mártir de Anglería. Estudio y edición trilingüe anotada en latín, español y árabe, Madrid, Instituto Egipcio de Estudios Islámicos y CantArabia Editorial, 2013.

ARANDA, Fray Antonio de, Verdadera información de la Tierra Sancta según la disposición en que en el año de mil y quinientos y treinta el autor la vio y passeó, Alcalá de Henares, Miguel de Eguía, 1533.

Buyza, Blas de, Relación nueva y copiosa de los sagrados lugares de Ierusalén y Tierra Santa, de las misericordias divinas que en ellos resplandece, de los muchos trabajos... Madrid, Viuda de Alonso Martín, 1622.

Calahorra, Fray Juan de, Chrónica de la provincia de Syria y Tierra Santa de Gerusalén. Contiene los progresos que en ella ha hecho la religión seráphica desde el año 1219 hasta el de 1632, Madrid, Juan García Infançón, 1684.

EIJÁN, Samuel, El Real Patronato de los Santos Lugares en la Historia de Tierra Santa, Tomo I y II, Junta de Relaciones Culturales, 1945. 
EIJÁn, Samuel, Hispanidad en Tierra Santa: actuación diplomática, Madrid, Obra Pía de los Santos Lugares de Jerusalén, 1943.

García Oro, José: "Fray Mauro Hispano, O.F.M. (1504-1506): un portavoz del "Soldán de Babilonia" en Europa", Homenaje al profesor Dario Cabanelas O.F.M., con motivo de su LXX aniversario, vol. I, Granada, 1987, pp. 345-354.

Gómez Redondo, Fernando, Historia de la prosa de los Reyes Católicos: el umbral del Renacimiento, Madrid, Cátedra, 2012, 2 vols.

Mártir de Anglería, Pedro, Una embajada de los Reyes Católicos a Egipto (según la Legatio Babylonica y el Opus epistolarum de Pedro Mártir de Anglería), ed. y trad. Luis García y García, Valladolid, Instituto Jerónimo de Zurita, 1947.

Lama de la Cruz, Víctor de, Relatos de viajes por Egipto en la época de los Reyes Católicos, Madrid, Miraguano, 2013.

Meseguer Fernández, Juan, "Franciscanismo de Isabel la Católica", Archivo Iberoamericano, 19 (1959), pp. 153-195.

Meseguer Fernández, Juan, "Isabel la Católica y los franciscanos (1451-1476)", Archivo Iberoamericano, 30 (1970), pp. 265-310.

MondÉJAR, Marqués de, Memorias históricas del Rey Don Alonso el Sabio, Madrid, Joaquín Ibarra, 1777.

Ochoa Brun, Miguel Ángel, Historia de la Diplomacia Española, IV, Madrid, Biblioteca Diplomática Española, 1995.

Ramos-Lissón, Domingo, "Jerusalén en el medievo español desde una perspectiva cristiana", Scripta theologica, 41 (2009/3), pp. 925-943.

Regestrum Observantiae Cismontanae: 1464-1488, (Analecta Franciscana 12), Grottaferrata (Roma), Collegium S. Bonaventurae, 1983.

SÁnchez Prieto, Ana Belén, "La intitulación diplomática de los Reyes Católicos: un programa político y una lección de historia", III Jornadas científicas sobre Documentación de la época de los Reyes Católicos, Madrid, Universidad Complutense, 2004, pp. 273-301.

San Juan del Puerto, Francisco Jesús María de, Patrimonio Seráphico de Tierra Santa fundado por Cristo Nuestro Redentor, Madrid, Imprenta de la causa de la V.M. María de Jesús de Ágreda, 1724.

Santisteban, Cristóbal de, Tratado de la sucessión de los reinos de Jerusalén y de Nápoles, Zaragoza, 1503.

Torre y del Cerro, Antonio de la, Documentos inéditos para la Historia de España, Tomo VII, Madrid, 1952.

Torre y del Cerro, Antonio de la, Documentos sobre relaciones internacionales de los Reyes Católicos, V, Barcelona, CSIC, 1949-1965. 